\title{
SUSTAINABLE URBAN DEVELOPMENT BY MEANS OF GREEN WALLS
}

DOI: 10.18485/arh_pt.2020.7.ch26

\author{
_ Budimir Sudimac \\ University in Belgrade - Faculty of Architecture, 73/2 Bulevar kralja Aleksandra St, \\ Belgrade, Serbia, sudimac@arh.bg.ac.rs
}

\author{
_ Aleksandra Ugrinović \\ University in Belgrade - Faculty of Architecture, 73/2 Bulevar kralja Aleksandra St, \\ Belgrade, Serbia, aleksandra.ugrinovic@arh.bg.ac.rs \\ _ Radojko Obradović \\ University in Belgrade - Faculty of Architecture, 73/2 Bulevar kralja Aleksandra St, \\ Belgrade, Serbia, robradović@hotmail.com
}

\section{ABSTRACT}

The use of green walls (also commonly referred to as living walls or vertical gardens) is not a new concept in building envelopes. Integrating vegetation in architectural structures may be a sustainable approach to the construction of façades of the new and existing structures. Green walls belong to the highly innovative and the fastest developing concepts of green building technology. This fact is supported by the examples of structures originally built with green walls which greatly add to the total visual appeal of buildings and are an important factor in the improvement of their thermal characteristics. Green walls have their own aesthetic values which are in direct correlation with human interaction aimed at creating visual diversity within urban spaces. Artistic perception of green walls of the recent era has radically changed, along with the new technological possibilities, their further development and application in the designing effort to formulate shape and materialization as a spatial structure with the already known aspects of traditional modelling. Green walls appear in space as elements carrying artistic application and sculptural creation in spatial architectural form of structures. Greening and preserving urban spaces have become important issues in considering conditions for designing architectural structures and redefining the relation between technology, energy and shaping, with the possibility of applying green walls in the architectural transformation process of the urban space. Green walls have raised new aesthetic issues, which are in direct correlation with technical solutions.

KEYWORDS _ Green wall, Integration, Technology

\section{INTRODUCTION}

The observation and analysis of building envelopes in different architectural structures through the history of architecture reveals the historical, economic, as well as cultural pattern of the society in which they arose.

Green walls are part of a growing conception of the new creative expression of building envelopes, dedicated to overcoming the challenges brought by global climate changes and natural resource depletion, and aiming at developing sustainable solutions for ensuring energy efficiency. At the same 
time, attaining the form-related norms allows these solutions to be accepted in the society at large, providing a new feature of form to modern buildings. Green walls open up an entire field of building envelope research, treating architectural structures as potential locales for artistic creation and implementation, and using technology as the basis of its expression. Vertical gardens are part of an integrative architectural expression and a basis for identifying and resolving form-related architectural tasks, as well as fulfilling the energy potentials of architectural structures.

Modern building envelopes aim for dynamism and an interactive relationship with the environment, making the most of the technological potential. Green walls are used as shading elements and for wind protection, especially in architectures adversely affected by the external factors (Figure1). In European medieval architecture, the use of vegetation, vine, and ornamental plants as elements of form was widespread in meeting aesthetic requirements, especially for open spaces. The mechanisms that allow the use of green walls as passive energy-saving systems are varied: shade provided by vegetation; the insulating qualities of the supporting façade element vegetation; and evaporative cooling.
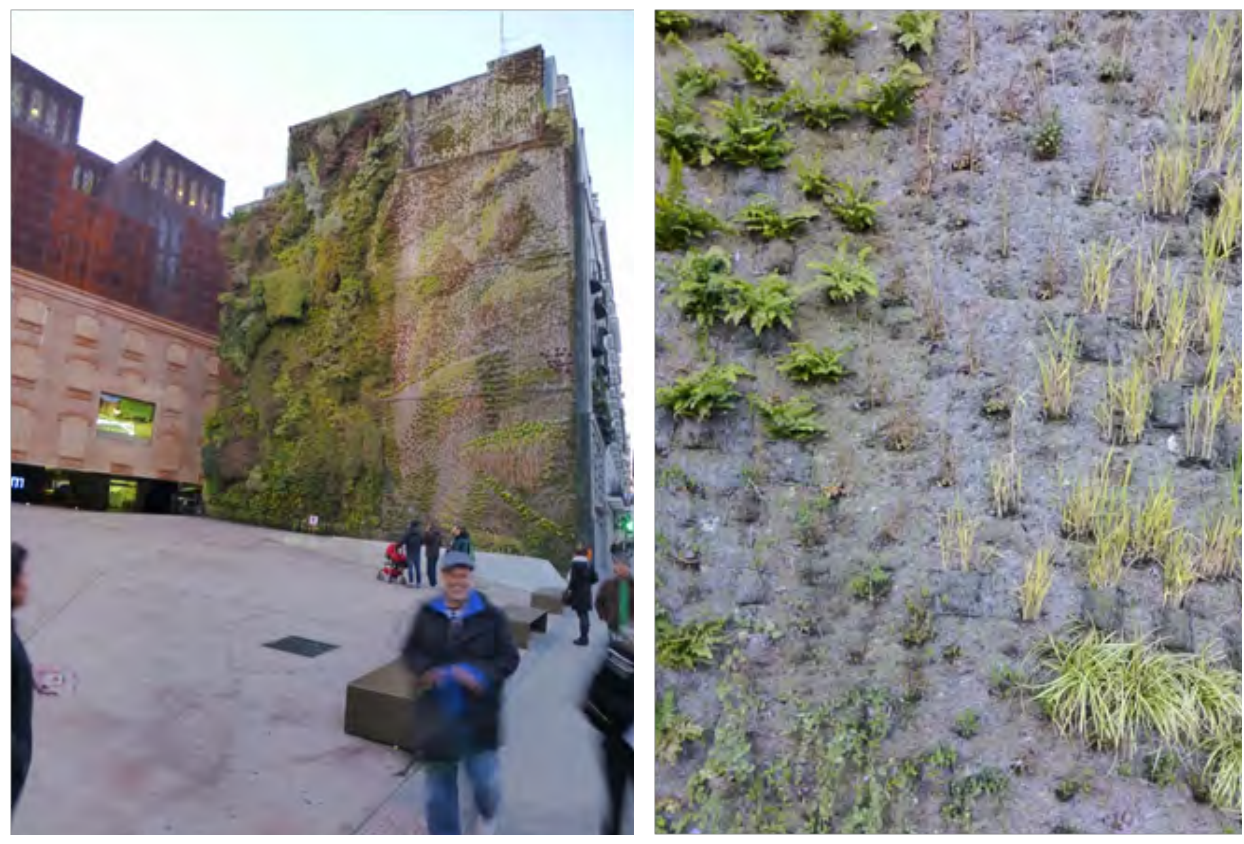

_ Figure 1. The impact of plant activity levels creating a green wall a) a green wall, b) a detail

Future buildings must implement a method of utilizing environmental conditions in resolving the issues relating to user comfort. Green walls are an example of a direct interaction between nature and physical structures. The vegetation envelope becomes a tool for resolving mounting environmental problems in urban surroundings. They become a design element in solving specific performance requirements and the shaping of building envelopes. Vegetation is an integral element of our everyday living. Green walls are classed as green façades with live wall systems. The need to develop green walls stems primarily from the need for an increased contact of the user with the elements of the environment. The need for contact is conditioned by the features of the location and the orientation of the building with a green wall. Green walls are classed as sustainable architecture, as the implementation of such concepts involves the application of modern materials and technologies, alongside an adequate evaluation of the climate conditions and the urban environment. 


\section{METHODOLOGY}

Green walls which change the observer's engagement with the building envelope from a static to a dynamic one have a great potential in densely-populated urban areas for improving the environmental sustainability factors. This primarily relates to big wall surfaces on which such advanced technological systems can be applied (Figure 2). Green walls are aimed at giving architectural structures a new character with respect to the environment, creating a new form, recognisability, and an interactive relationship with the environment. The positive effects of green walls depend on numerous factors.

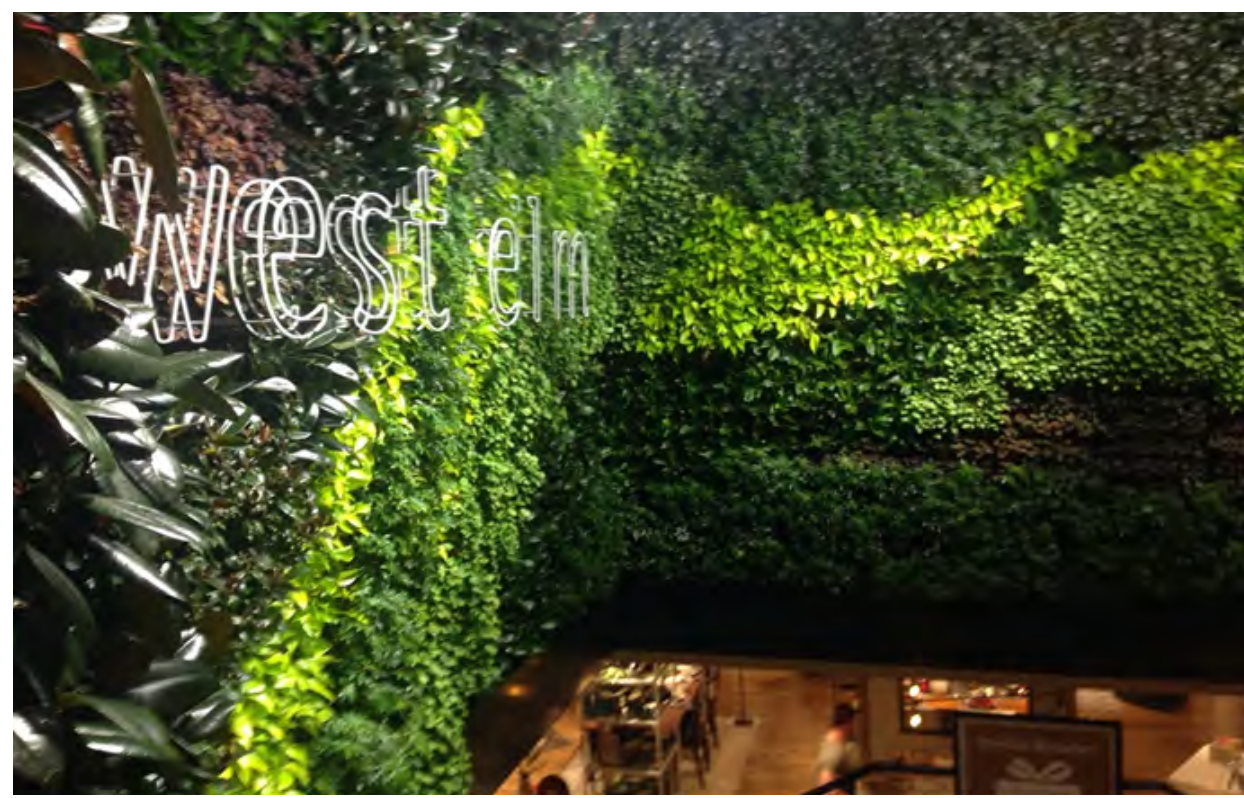

_ Figure 2. Green walls as elements of recognisability

The main factors in achieving these effects are as follows: the green wall design - relating first and foremost to the total wall surface area; the density and size of leaves; the types of plants used; green wall orientation; and the maintenance level. In the process of transforming the urban space by means of a green wall, it is necessary to open a specific sort of communication between the user and the environment. 'The future of our communities, natural resources, and ecosystems depends on how much we understand, appreciate, and protect the habitats and species which sustain our world. We need to be proactive and provide our children and adults with the tools to identify the effects of changeability.

\section{VISUAL IDENTITY}

Green walls acquire additional value through elements of form-related difference, giving a building and its envelope an entirely new visual identity by using plants materials (Figure 64). Green walls appear as integrated sustainable solutions in building envelopes, $s$ well as a solution for small-scale spatial interactions. Green walls become a symbol of green or eco-architecture, as they can be identified easily, being visible and having a direct impact on the total green area in urban environments. Through its visual identity, vegetation contributes not only to the identification of the building itself, but also has a significant role in the creation of the locale identity. One of the basic requirements 
in architecture is for a building to send an aesthetic message in a public space. Green walls allow this, but in addition to this message, they also contribute to an increase in biodiversity in urban environments, urban agriculture, recycling sites, and health improvements. Green walls can alleviate to an extent the lack of bio-equality in urban environments, as well as sustain specific plant species and provide habitats and nesting grounds for insects and various types of birds. Green walls are a natural extension of their environments. The research by a number of authors (Honeyman 1987) has shown that buildings with green walls have positive effects on human health, and that the visual contact with replanting stock and artistic creations results in increased satisfaction with being and working in such spaces, and therefore in increased productivity as well (Kaplan 2001). An especially important paper (Ulrich 1983) points to more successful postoperative recovery of patients in buildings providing a direct interaction with a green wall. Urban agriculture is an underexplored area of green wall implementation. Researchers conclude that green walls have an indisputable potential in developing urban agricultural replanting stock, with evident general utility (Figure 3a, b). In urban environments and urban overcrowding locations, where land is expensive and scarce, green walls can be used as a suitable site for the implementation of such ideas.

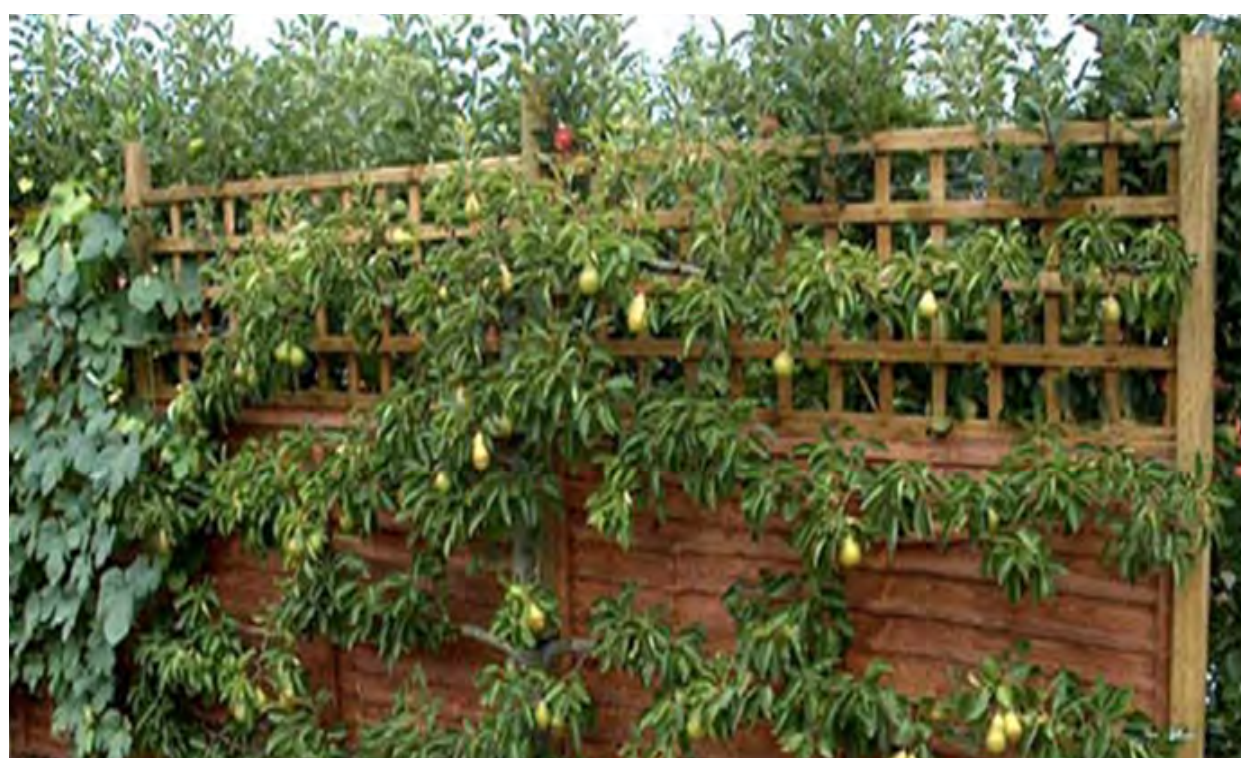

_Figure 3. Urban agriculture

'The basic characteristic of urban agriculture is local food production for local use - a closed system of supply within the local community which offers many advantages: the recultivation of non-landscaped urban areas, employing the populace, more food and a healthier diet, increased economic power of a city and its inhabitants, stronger ties among the populace.'

\section{THE SPATIAL AND ORGANIZATIONAL ASPECTS}

The wish on the part of the designer to give an essentially different meaning to vegetation in buildings, on top of the simple logical functionality, is made possible by the complex technological development of such systems. The initial reflections and the technological level of the time at which the first green walls were made were limiting with regard to their realisation, compared to what is available to creative professionals today. At present, the technical aspects of the implementation, first and foremost of green wall maintenance, are often overshadowed by the visual requirements and 
creative goals. Making use of all available technological means and designing new ones, green wall designers build green walls as new assembly motifs, elements central to architectural works, utilizing the principles of symmetry or asymmetry, the elements of ordered disorder. Using vegetation as a material which in the earlier architectural periods was not used for the construction and shaping of architectural structures, creating a new structure, and defying the laws of nature, they expanded the freedom of their own creative enterprise. In addition to their primary functional form, green walls also appear in space as elements carrying the artistic implementation, as sculptural creations in the spatial layout of architectural structures (Figure 3). Green walls take on the role of an artist's canvas, providing the authors with a new medium of expression, and space with a certain sculptural form. Using vegetation in the finishes does not mean material wealth; rather, it is a meaningful, interesting, yet complex sculptural character of the green wall. In some cases, green walls transform into the dominant artistic expression in the space in which they are situated, owing to designing explorations of the potential of the material that they are made of and new structural systems. It should be added that the appearance of green walls in architecture partly arises from the human beings' need for contact, knowledge, and stimulation.

\section{The formal aspect}

Green walls have their form-related values which are directly correlated with human interaction geared towards visual diversity in the urban space. Jan Gehl identifies a site always pleasant to the eye as a 'common characteristic of all optional activities - they occur only when the external conditions for stopping and moving are good and when it is pleasant to be in an environment.' A proper view of vegetation is what largely defines the appearance of a green wall, due to seasonal changes and the adaptation of vegetation to these cycles in temperate climate conditions. If we see a green wall as an architectural element (Figure 4) which should attain the highest level of attraction through its form and function, then vegetation must adapt to the temperature differences at different times of the year. All these changes can have a significant impact on the perception of the green wall form. Therefore, some urban spaces undergo constant transformation.

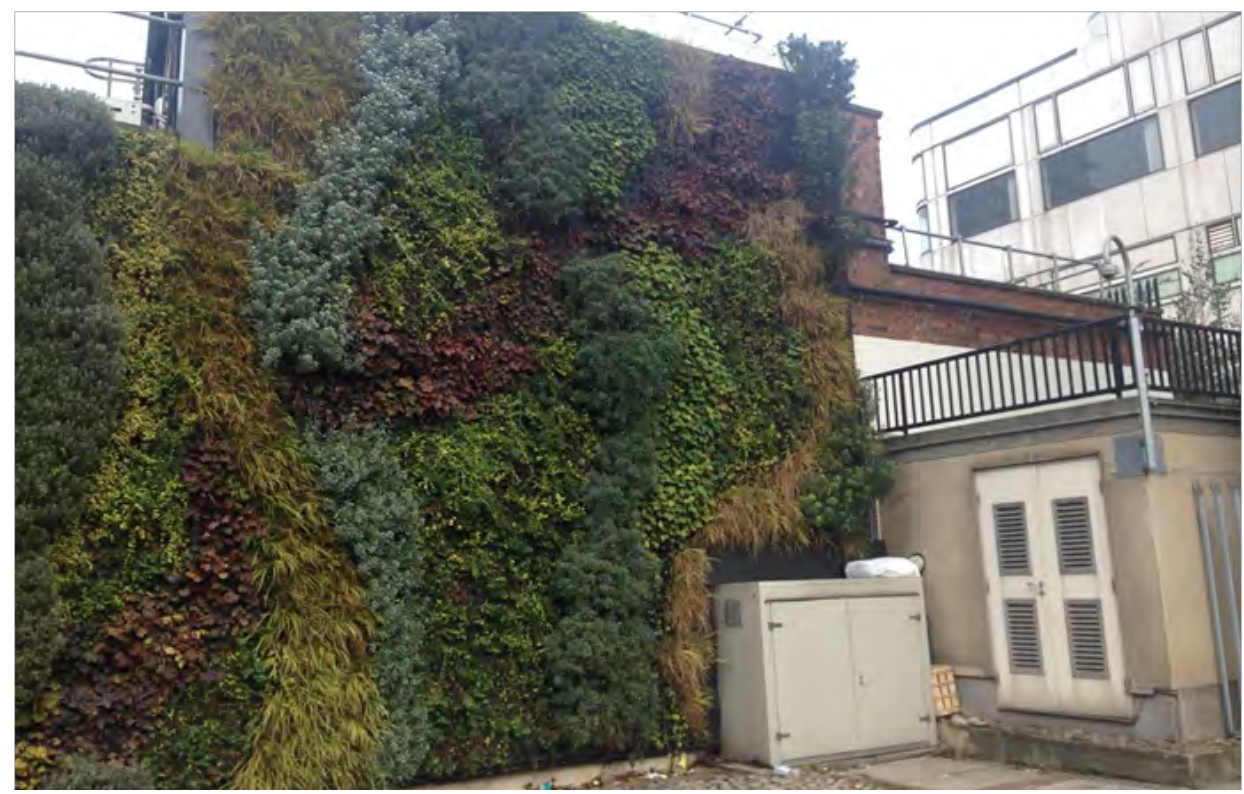

- Figure 4. Green walls as architectural elements 


\section{The functional aspect}

The building envelope as a basic element in the identification of a structure dominates space primarily through its constructional features. The implementation of the envelope is directly linked to the construction of the façade, using the material that the main construction system is made of with the aim of achieving the final visual identity of a structure. The functional requirements of public buildings, the construction norms defined in normative documents, the architectural inclinations of the designers, construction solutions, awareness of the static and form-related characteristics, the spatial comfort, the interaction between specific architectural elements in the space where the façade is located determine the form and design of the green wall. "Art provides form, and form alone makes something a work of art. Form is not random, arbitrary or irrelevant (nor is it so with crystals). The laws and conventionality of form are an embodiment of man's power over matter; they preserve experience and provide two achievements; they are the order that both art and life require. Form is also conditioned by materials to a certain extent."

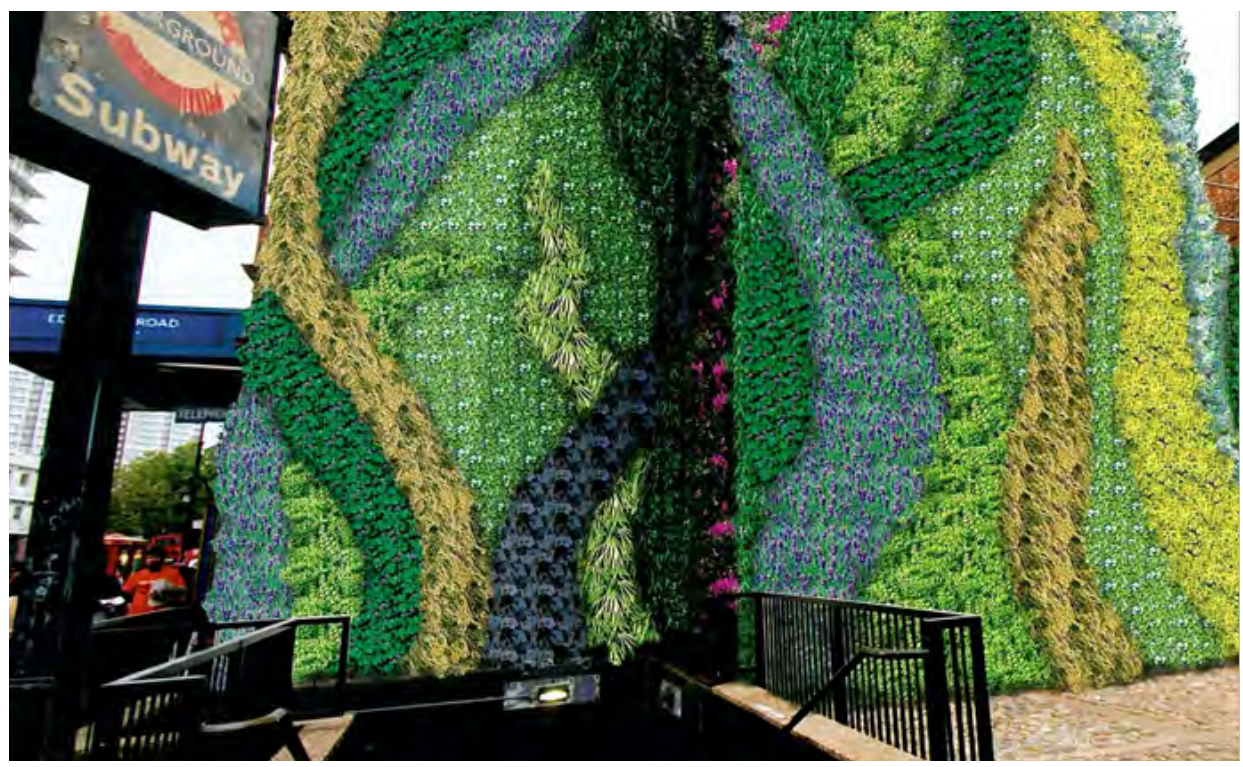

_ Figure 5. Green walls as elements of urban space design

\section{The technological aspect}

The development of technology largely determines the dynamic of the development and use of green walls as a tool of expression in implementing architectural structures. Urban spaces are undergoing a significant transformation nowadays, owing to innovative designer solutions drawing inspiration from the theoretical foundations characterizing the modern world. In terms of the typology of architectural structures, above all multi-storey car parks, urban streets (Figure 5) with repeating façades, transit warehouses, and retail facilities all offer an opportunity to use green walls to improve spatial form to an extent, as well to transform the urban space. Green walls allow the creation of certain implementational patterns by using vegetation textures as the main elements of expression. Abandoned, dilapidated, or partially collapsed buildings are ideal sites for mounting green walls with the aim of transforming and raising the identity level of urban spaces.

\section{The energy-related aspects}

Some research has pointed to the significant role of green walls in reducing winter heat loss and summer heat gain in facilities or walls where implemented. Traditional building materials have a high degree of thermal conductivity. The analyses show that green walls reduce the overheating of 
such walls during summer months, thus reducing the total amount of energy used for air conditioning of a structure. Green walls do not accumulate heat as much as walls made of conventional materials. Numerous factors affect the level of heat loss or heat gain reduction in buildings with green walls, the most significant ones being the orientation of the green wall, the structure of greenery in it, the size of leaf surface, thickness of the leafy part of plants, and soil humidity.

The energy potential of a certain building facing is determined by its structure, local weather conditions, and the facility usage regime. Green facings add to the amount of vegetation in stuffy urban spaces, provide unique visual appeal, and increase the ambient values of their surrounding. Integrating vegetation into structures can be a sustainable approach to building façades of both new and existing buildings. At the same time, vertical landscape walls improve the energy-related capacities of facilities, contribute to biodiversity, add the aesthetic values, and play a significant part in reducing the air pollution caused by fine dust particles and carbon dioxide. In order to find the new models of green walls that would have strong energy potential in our climate, it is necessary to define the proper parameters for comfort first, by respecting the prescribed thermal characteristics of facings.

There are three major phases in incorporating a green wall: programming it, designing, and finally building it. The green wall design requirements are directly conditioned by the type of a building, the position of the desired green wall within it, and the technology used. Each of these requirements affect the other two, pointing to a very complex demand scheme in designing green walls. The choice and the position of a green wall withing a facility primarily depend on the programming context and are extremely dependable of the building's economic aspect and the appearance. All types of green walls can conveniently be incorporated in the desired goals of a building design, although the choice is dictated by the specific conditions and the design itself.

\section{CONCLUSION}

Compared to other architectural elements, green walls dominate buildings architecturally, technologically, and form-wise. Designing and constructing them requires following the technological development in construction as well as in other areas, as over time new systems are developed for their implementation, ensuring greater comfort in use. Form-wise, green walls can be seen in terms of the following parameters: the visual identity of green walls; and the parameters for assessing the form-related characteristics of green walls. Green wall architecture now makes use of a new approach to form, a new functional interpretation, and new construction solutions, which cannot always be classed as economically justified and cost-effective. Invention in design, with the help of technology, is left without rules and constraints in all the aspects of the design and construction of green walls.

The replanting stock as the carrier of the form-related characteristics of green wall architecture creates a certain visual relationship in space by means of its composition and inter-connections, both in terms of positionality and the individual composition. The space where a green wall is located is shaped primarily by means of mass, and is characterized by the interrelationships, the features of the components, plant types, as well as by colour, texture, the full-empty interplay, and rhythmicality. Green walls created by planting a large vegetation stock, placed in a specific layout, whose position in the composition affects the visual presentation on the building envelope, provide a certain value and visual character that persists in time. Visual appeal of the wall itself 'lies in the striving for freedom from non-aesthetic content - their aesthetic function is not secondary, peripheral, or merely external (as is the case in an array of more recent art disciplines whose aesthetic status is still being constituted and defined, or still has an experimental character).' The form of a green wall is also defined by the positional characteristics of the wall in question with respect to the other architectural elements, the viewing angle, and the distance of the observer. The composition of the wall is conditioned first and foremost by integrativity, proportionality, balance, and harmony of elements, and their rhythm and repetition frequency, symmetry, asymmetry, harmony, and modularity. 
The modern technology of green wall construction allows new green wall forms to be implemented, giving green walls new aesthetic values in the process. Green walls will gain importance in architecture, as the decrease of the conventional energy carriers has resulted in the discovery of new and renewable energy sources. The architecture of the future requires new means of expression in formulating its own identity, and green walls are a provocative material for architectural expression. All this will depend on the users' cultural awareness, social trends, architectural thought, and technological development. The development of green walls in the future will probably tend towards identifying new media of expression in implementing green walls, the development of energy-efficient modular systems, and a multidisciplinary approach in future research and impact of green walls on architectural structures.

\section{REFERENCES}

_ Attia, S., et al. "Architect Friendly" : a comparison of ten different building performance simulation tools. in IBPSA Conference. 2009. Glasgow, Scotland: International Building Performance Simulation Association.

_ Bartfelder,F., M. Köhler.: Experimentelle untersuchungen zur function von fassadenbegrünungen, Dissertation TU Berlin 612S, 1987.

_ Blom, L. Itard, A. Meijer,: LCA-based environmental assessment of the use and maintenance of heating and ventilation systems in Dutch dwellings, Building and Environment 45 (2010) 2362-2372.

- Cuce, E., Thermal regulation impact of green walls: An experimental and numerical investigation. Applied Energy 2017; 194:247-254.

_ Dunnett N, Kingsbury N.: Planting green roofs and living walls. Portland, Or: Timber Press; 2008, VII, p.328.

_ Dimitrijevic, D., et al., Green living roof implementation and influences of the soil layer on its properties, Thermal Science, vol.20 (2016), Suppl 5, pp. S1511-S1520

_ Grant G. : Green roofs and facades. Bracknell: IHS BRE Press; 2006.

_ Eumorfopoulou, E.A, K.J. Kontoleon,: Experimental approach to the contribution of plant covered walls to the thermal behaviour of building envelopes, Building and Environment 44 (2009) 1024-1038

- Fjeld, T., Bonnevie, C.,: The effect of plants and artificial day-light on the well-being and health of office workers, school children, and health care personnel, in International Horticultural Exhibtion Floriade 2002. 2002.

- Harmati, N., et al., Building envelope influence on the annual energy performance in office buildings, Thermal Science, vol.20 (2016), No 2, pp. 679-693

_ Kaplan, S.,: The restorative benefits of nature: Toward an integrative framework. Journal of Environmental Psychology, 1995. 15(3): p. 169-182.

_ Köhler, M.: Green Facadesa view back and some visions. Urban Ecosystems 2008. 11(4): 423-436.

_ Lam M, Ip K, Miller A.: Experimental modelling of deciduous climbing plants as shading devices. In: Sustainable buildings 2002 - third international conference on sustainable buildings. Oslo, Norway: EcoBuild; 2002.

_ Miller A, Shaw K, Lam M.: Vegetation on building facades: "Bioshader". Case Study Report; 2007.

_ Papadakis, G., Tsamis, P. \& Kyritsis, S., :An experimental investigation of the effect of shading with plants for solar control of buildings. Energy and Buildings, 33, 2001. pp. 831-836.

_ Peck, S.W. et al., Greenbacks from Green Roofs: Forging a New Industry in Canada, Status Report on Benefits, Barriers and Opportunities for Green Roof and Vertical Garden Technology Diffusion, Environmental Adaptation Research Group, Canada, 1999.

- Pejic, P., et al., The effect of architectural façade design on energy savings in the student dormitory, Thermal Science, vol. 18 (2014), No 3, pp. 979-988

_ Perini K., et al., The use of vertical greening systems to reduce the energy damand for air conditioning. Field monitoring in Mediterranean climate. Energy and Buildings 2017; 143:35-42. 
- Saelens,D.,Blocken, B., Roels,S., Hens,H.: Optimization of the energy performance of multiple-skin facades, in: Ninth International IBPSA Conference, Montreal, Canada, August 15-18, 2005.

- Sunakorn P, Yimprayoon C.: Performance of facade greening in the tropical region. Journal of Energy 2007. Bangkok: Energy Research Institute, Chulalongkorn University; vol.9/2551: 50-64.

- Sudimac B., Anđelković A., Dubljević S.: Thermal extras of vegetation walls in Belgrade climatic conditions, Thermal sciences (2018), doi:10.2298/TSCI170919027S

- Susorova I., et al., A model of vegetated exterior facades for evaluation of thermal performance. Building and Environment 2013; 67:1-13.

- Tudiwer D, et al., The effect of living wall systems on the thermal resistance of the facade. Energy and Buildings 2017; 135:10-19.

- Wolverton,B.C., Johnson,A.,Bounds,K.: Interior landscape plants for indoor air pollution abatement, Interiorscape (11) (1989) 37-63. 